\title{
In vitro assessment of the accuracy of extraoral periapical radiography in root length determination
}

\author{
Muhammad Rizwan Nazeer ${ }^{1}$, Farhan Raza Khan ${ }^{1}$, Munawwar Rahman ${ }^{1}$
}

\author{
Correspondence: Dr. Muhammad Rizwan Nazeer \\ Email: dr.rizwannazeer@gmail.com
}

\author{
'Operative Dentistry, Section of Dentistry, Aga Khan \\ University Hospital, Karachi, Pakistan
}

\section{ABSTRACT}

Objective: To determine the accuracy of extra oral periapical radiography in obtaining root length by comparing it with the radiographs obtained from standard intraoral approach and extended distance intraoral approach. Materials and Methods: It was an in vitro, comparative study conducted at the dental clinics of Aga Khan University Hospital. ERC exemption was obtained for this work, ref number 3407Sur-ERC-14. We included premolars and molars of a standard phantom head mounted with metal and radiopaque teeth. Radiation was exposed using three radiographic approaches: Standard intraoral, extended length intraoral and extraoral. Since, the unit of analysis was individual root, thus, we had a total of 24 images. The images were stored in VixWin software. The length of the roots was determined using the scale function of the measuring tool inbuilt in the software. Data were analyzed using SPSS version 19.0 and GraphPad software. Pearson correlation coefficient and Bland-Altman test was applied to determine whether the tooth length readings obtained from three different approaches were correlated. $P=0.05$ was taken as statistically significant. Results: The correlation between standard intraoral and extended intraoral was 0.97 ; the correlation between standard intraoral and extraoral method was 0.82 while the correlation between extended intraoral and extraoral was 0.76 . The results of Bland-Altman test showed that the average discrepancy between these methods is not large enough to be considered as significant. Conclusions: It appears that the extraoral radiographic method can be used in root length determination in subjects where intraoral radiography is not possible.

Key words: Dental phobia, exaggerated gag reflex, extraoral periapical radiograph, film holder, intraoral periapical radiograph, radiographic methods

\section{INTRODUCTION}

Radiographic examination is one of the primary diagnostic tools used in dentistry to determine a disease state and to formulate an appropriate treatment plan. ${ }^{[1]}$ At present, various radiographic techniques are employed for orofacial imaging. A periapical radiograph is the most frequently prescribed radiograph in dental practice. Intraorally, a periapical radiograph can be obtained either by a paralleling or a bisecting angle technique, in which paralleling method is the commonly employed approach. ${ }^{[2]}$

Certain indications for periapical radiograph include detection of dental caries, periapical pathologies, assessment of periodontal status, and root morphology before extraction, trauma to teeth and the associated structures, assessment for implant surgery as well as in endodontic procedures. ${ }^{[2]}$ During root canal therapy, determination of the working length of the tooth is the most essential step in subsequent steps such as cleaning, shaping, and obturation of the root canal system cannot be performed without accurate working length estimation. ${ }^{[3]}$ Failure to obtain accurate working length can cause certain procedural complications such as ledge formation, apical perforation, over or under filling ${ }^{[4,5]}$ which can ultimately reduce the success rate of root canal therapy. ${ }^{[4]}$

In some patients, obtaining a correct intraoral periapical radiograph can be very difficult. These

This is an open access article distributed under the terms of the Creative Commons Attribution-NonCommercial-ShareAlike 3.0 License, which allows others to remix, tweak, and build upon the work non-commercially, as long as the author is credited and the new creations are licensed under the identical terms.

For reprints contact: reprints@medknow.com

How to cite this article: Nazeer MR, Khan FR, Rahman M. In vitro assessment of the accuracy of extraoral periapical radiography in root length determination. Eur J Dent 2016;10:34-9.

DOI: $10.4103 / 1305-7456.175681$ 
include individuals with the severe gag reflex, pediatric patients who are reluctant to intraoral film placement, patients with macroglossia or microstomia, postradiation therapy patients with trismus or patients with limited sulcus depth, etc. ${ }^{[6]}$ For such patients, Newman and Friedman ${ }^{[7]}$ introduced an alternative technique in which diagnostic periapical radiographs were taken by using extraoral approach. The film was placed on the cheek adjacent to the buccal surface of tooth and $X$-ray beam were exposed from the opposite side of the face. In 2007, a device was developed by Chen et al. ${ }^{\left[{ }^{[8]}\right.}$ which can be used successfully to obtain X-ray by extra-oral technique. Studies have been published in which diagnostic X-ray are successfully obtained using extraoral approach. ${ }^{[6,9-12]}$

Hence, the aim of the study was to evaluate the accuracy of extra oral periapical (EOPA) radiograph for determining working length by comparing it with two other sets of radiograph obtained with intraoral approaches.

\section{MATERIALS AND METHODS}

This in vitro experimental study was carried out in dental clinics of Aga Khan University Hospital Karachi, Pakistan. The Ethical Review Committee of the Institution approved the study (reference number 3407Sur-ERC-14). We carried out an in vitro experimental study for which we used phantom head mounted with radiographic training models in which premolar and molar teeth were included as part of inclusion criteria. The radiopaque metallic teeth casts were our experimental model.

Periapical radiographs of upper and lower premolar and molars were obtained from three different approaches; so we divided our images into three groups depending on the technique used.

- Group A: Standard intraoral [Figure 1]

- Group B: Extended distance intraoral [Figure 2]

- Group C:Extra periapical oral radiograph [Figure3].

8 teeth/side exposed with three radiographic approaches gave us a total 24 images for Group A images we used standard cone indicating device. For Group B, the same cone indicating the device was used but with an X-ray source to sensor distance of $160 \mathrm{~mm}$ as verified by a ruler scale. For Group C images, we have attempted to develop a customized beam aiming device as suggested by Chen $e t$ al. ${ }^{[8]}$

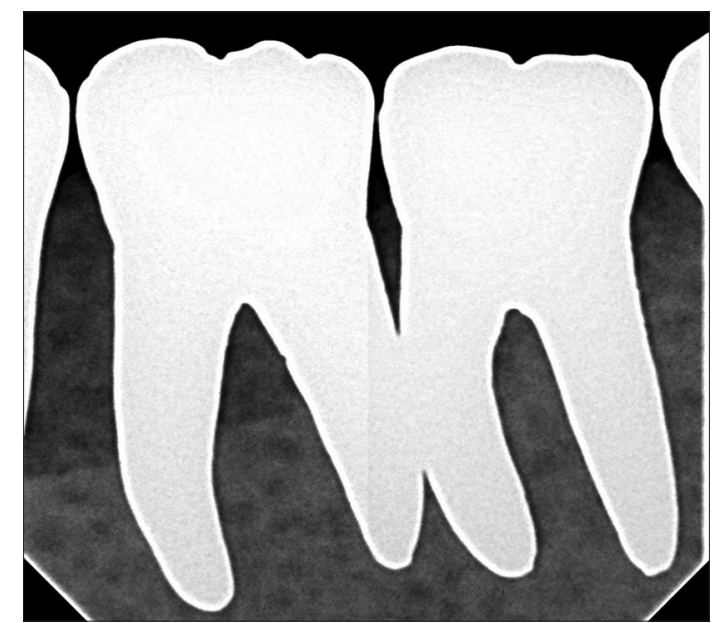

Figure 1: Periapical radiograph of mandibular left first molar taken from standard intraoral approach

\section{Armamentarium of customized beam aiming device} for extraoral periapical radiograph

Following are the components of aiming device which was designed for EOPA radiographs:

- Two locator rings for bitewing radiography (Rinn, Dentsply, York, PA)

- Two metal supporting indicator rods

- A bite block for horizontal bitewing radiography.

\section{Assembling the components}

The two metal indicator rods were inserted into two locator rings. The bite block was attached to one end of the indicator rod, and the sensor was firmly tied to the bite block. The two metal indicator rods were finally soldered. The reason for soldering rods instead of using rubber tube is to provide a stable and more rigid support during imaging as shown in Figure 4.

Gendex digital X-ray imaging system was used to obtain radiographs using three approaches described earlier. The voltage and ampere settings were kept constant at $70 \mathrm{kV}$ and $15 \mathrm{mAs}$ respectively. The duration time was kept constant at $0.8 \mathrm{~s}$. Although, there is a negligible risk of harm with the use of digital radiograph but lead apron was worn by the investigator to prevent any radiation hazards.

\section{Technique for extraoral periapical radiograph}

The phantom head was connected to the dental, with its mouth opened as wide as possible, so that for extraoral images the X-ray beam can pass to the sensor in an unobstructed manner from the opposite side of the mouth. The sensor was then placed on the external surface of the cheek, directly buccal to the tooth. The X-ray cone was angled -20 to $-30^{\circ}$ for 


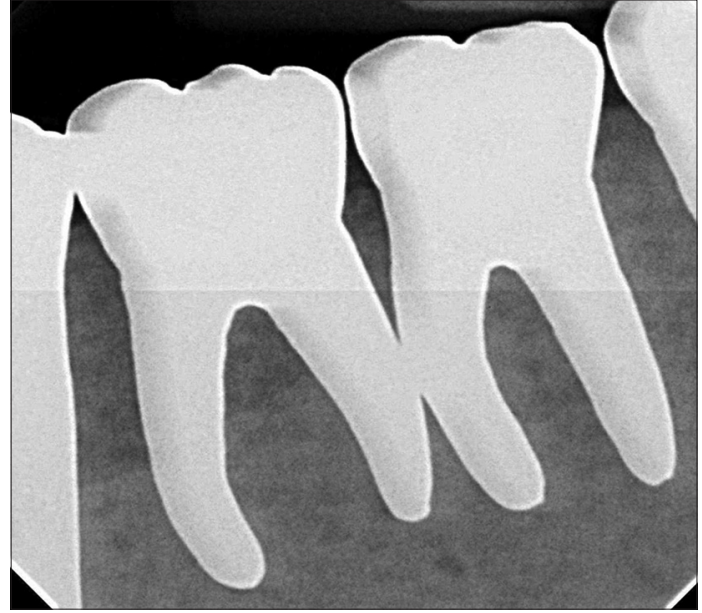

Figure 2: Periapical radiograph of mandibular left first molar taken from extended distance intraoral approach

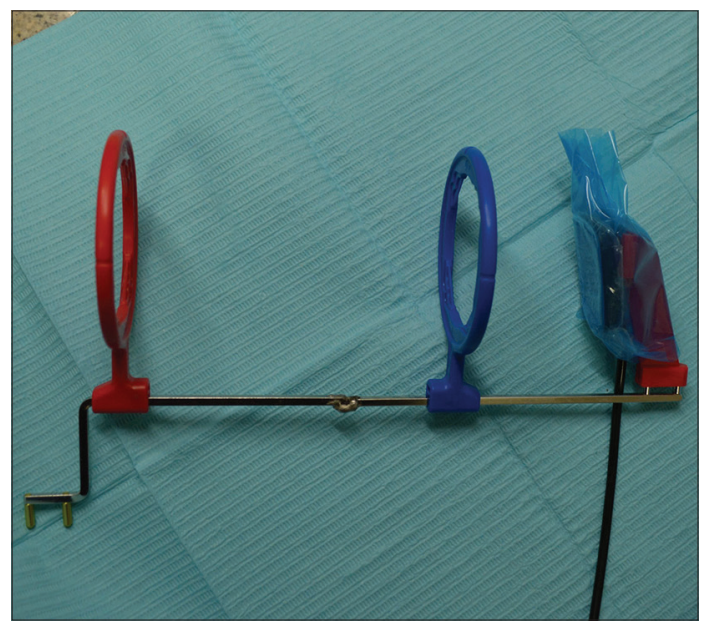

Figure 4: Customized beam aiming device used for extraoral periapical radiograph

maxillary premolar and molar teeth and +20 to $+30^{\circ}$ for the mandibular premolars and molars from the horizontal plane [Figure 5].

The images were stored in VixWin software version 1.5 by Accusoft soft corporation, the USA already installed in our dental clinic setup. The length was determined using the scale function of the measuring tool inbuilt in the software.

Data were analyzed using SPSS for Windows (version 19.0, SPSS Inc. Chicago, USA). The mean and standard deviation of the root length of the three groups was computed. Pearson's correlation test was used to measure the strength and direction of association that exists between different radiographic techniques. Bland-Altman plot was used to assess whether these approaches were interchangeable. $P=0.05$ was taken as statistically significant.

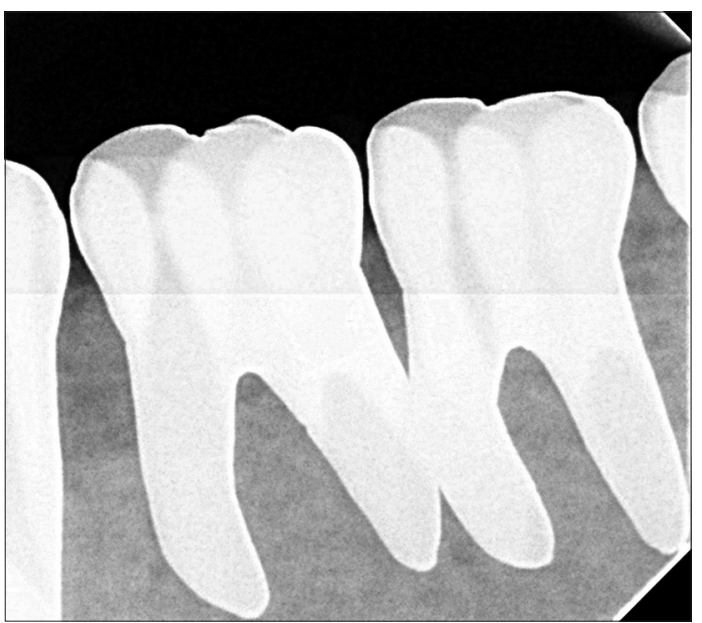

Figure 3: Periapical radiograph of mandibular left first molar taken from extraoral approach

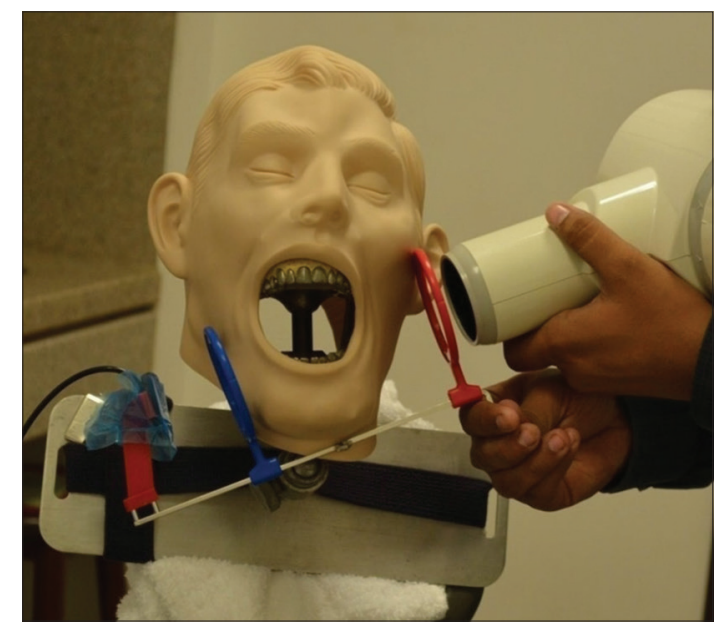

Figure 5: Extraoral periapical radiographic method for mandibular teeth using custom beam aiming device

\section{RESULTS}

Length of the roots obtained from three different approaches were analyzed using SPSS version 19.0 and GraphPad software (Prism 6 GraphPad Inc., California, USA) Pearson's correlation coefficient was derived to measure the strength of the association between the two variable techniques. The correlation between standard intraoral and extended intraoral was significant and found to be 0.97; correlation between standard intraoral and extraoral method was again significant and turned out to be 0.82 while correlation between extended intraoral and extraoral method was 0.76 as shown in Table 1.

Bland-Altman plot was drawn by plotting the differences between the two techniques against the averages of the two techniques. The results 
of Bland-Altman test showed that the average discrepancy between these methods is not large enough to be considered as significant as shown in Graphs 1-3.

\section{DISCUSSION}

For successful nonsurgical root canal therapy and minimizing postoperative discomfort, it is necessary that root canal system should be thoroughly debrided. One of the most important steps in root canal preparation is the determination of precise working length. All other steps of the procedure such as cleaning, shaping, and obturation cannot be preceded without determining the correct working length. ${ }^{[13,14]}$

There are various methods of determining root canal length which includes radiographs, apex locaters, tactile sensation, and other adjunctive methods but the radiographic method is being the most common employed for measuring working length. ${ }^{[15,16]}$

The most common radiographs used for working length determination are intraoral periapical radiograph. ${ }^{[17]}$ However, it is difficult to obtain ideal periapical radiograph in certain cases such as patients with trismus, exaggerated gag reflex, pediatric patients, patients maxillary, and mandibular tori or patients with dental phobia, etc. ${ }^{[2]}$ and the thick and rigid sensor of digital radiograph are increasing the pool of patients. ${ }^{[18]}$ For such patients, Newman and Friedman introduced an alternative technique in which diagnostic periapical radiographs were taken by using extraoral approach. The film was placed on the cheek adjacent to the buccal surface of tooth and X-ray beam were exposed from the opposite side of the face. To avoid overlap, the patient is asked to open mouth as wide as possible, and the X-ray cone is angled approximately $-55^{\circ}$ for the maxilla and for mandibular teeth the angle is $-35^{\circ} .^{[7]}$ In 2007, a device was developed by Chen et al., which can be used successfully to obtain X-ray by extra-oral technique.

\begin{tabular}{|c|c|c|c|}
\hline \multicolumn{4}{|c|}{ Correlations } \\
\hline & Standard intraoral & Extended intraoral & Extraoral \\
\hline $\begin{array}{l}\text { Standard } \\
\text { intraoral }\end{array}$ & 1 & $\begin{array}{l}0.969^{\star *} \\
<0.001\end{array}$ & $\begin{array}{c}0.826^{\star *} \\
0.001\end{array}$ \\
\hline $\begin{array}{l}\text { Extended } \\
\text { intraoral }\end{array}$ & & 1 & $\begin{array}{c}0.762^{* *} \\
0.004\end{array}$ \\
\hline Extra oral & & & 1 \\
\hline
\end{tabular}

${ }^{* *}$ Correlation is significant at 0.01 level of significance
Chen et al., also advocated a lesser vertical angulation as compare to Newman and Friedman, i.e., -20 to -30

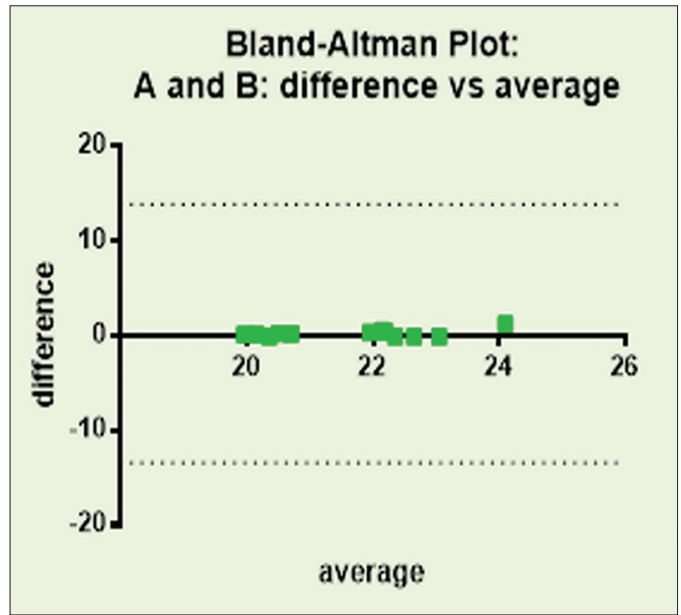

Graph 1: Bland-Altman plot comparing standard intraoral periapical technique with the extended distance intraoral technique

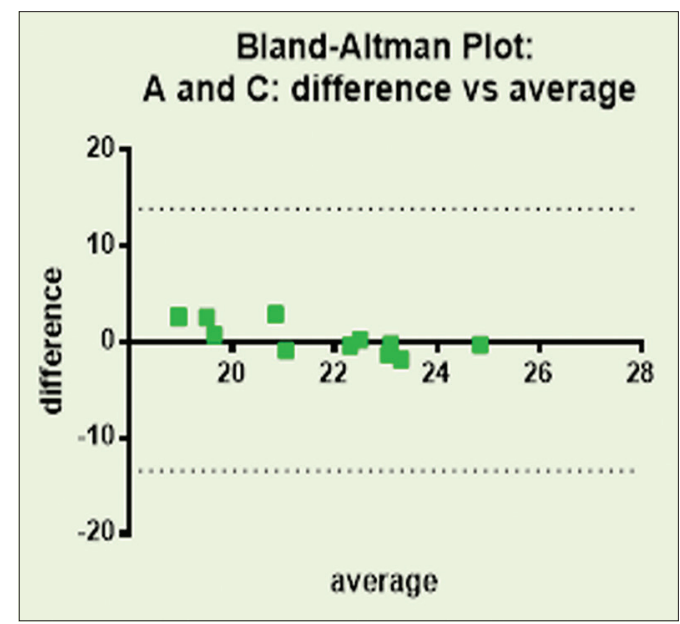

Graph 2: Bland-Altman plot comparing standard intraoral periapical technique with the extra-oral periapical technique

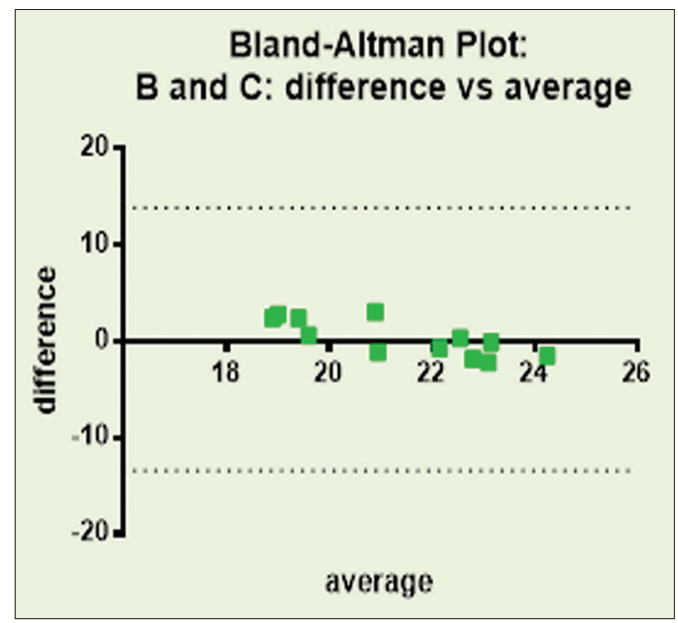

Graph 3: Bland-Altman plot comparing extended distance intraoral technique with extra-oral periapical radiographic technique 
for maxillary teeth and -10 to -15 for mandibular teeth. ${ }^{[8]}$

Saberi et al. in $2012^{[11]}$ modified Newman Friedman radiographic technique by giving certain anatomic landmarks while testing the techniques on phantom head models. The vertical angulation modified by Saberi et al. is $-25^{\circ}$ for the maxilla and $-20^{\circ}$ for the mandible with $10^{\circ}$ head tilt toward the side being examined.

However in a study conducted by Reddy et al. ${ }^{[9]}$ suggested -20 to -30 for maxillary teeth and +20 to +30 for the mandible. In our study, we used then angulation suggested by Reddy et al. ${ }^{[9]}$ and a $10^{\circ}$ tilt that was suggested by Saberi et al. ${ }^{[11]}$ The comparisons of the aforementioned studies are summarized in Table 2.

An in vivo study, ${ }^{[10]}$ evaluating the accuracy of EOPA radiograph was reported to be $94.6 \%$ and another study conducted by Sudhakar et al., ${ }^{[12]}$ it was found to be $90.7 \%$ but in our study it was found to be $82.6 \%$. However, EOPA technique has few limitations. This technique cannot be used to obtain radiographs of anterior maxillary and mandibular region due to the curvature of arch and difficulty in the positioning of the $\mathrm{X}$-ray cone. The procedure is technique sensitive and requires proper knowledge and experience.

There are few limitations of EOPA. This technique is not indicated for anterior teeth radiograph because of the arch curvature and difficulty in positioning cone

\begin{tabular}{|c|c|c|c|}
\hline $\begin{array}{l}\text { Author/journal/ } \\
\text { year }\end{array}$ & $\begin{array}{l}\text { Vertical } \\
\text { angulation }\end{array}$ & Study & $\begin{array}{c}\text { Accuracy } \\
(\%)\end{array}$ \\
\hline $\begin{array}{l}\text { Newman and } \\
\text { Friedman/ } \\
\text { JOE/2003[7] }\end{array}$ & $\begin{array}{l}-55 \text { for } M a x \\
-35 \text { for } M n\end{array}$ & $\begin{array}{l}\text { Case report/ } \\
2 \text { images }\end{array}$ & NA \\
\hline $\begin{array}{l}\text { Chen et al./ } \\
\text { JOE/2007 }\end{array}$ & $\begin{array}{l}-20 \text { to }-30 \text { for } \mathrm{Max} \\
-10 \text { to }-15 \text { for } \mathrm{Mn}\end{array}$ & In vivo/24 images & NA \\
\hline $\begin{array}{l}\text { Reddy et al./ } \\
\text { JIAOMR/2011 }\end{array}$ & $\begin{array}{l}-20 \text { to }-30 \text { for } M a x \\
+20 \text { to }+30 \text { for } M n\end{array}$ & In vitro/NA & NA \\
\hline $\begin{array}{l}\text { Saberi et al./ } \\
\text { IEJ/2012 }\end{array}$ & $\begin{array}{l}-25 \text { for } M a x \\
-20 \text { for } M n \\
10^{\circ} \text { tilt }\end{array}$ & $\begin{array}{l}\text { In vitro, mannequin } \\
\text { head/NA }\end{array}$ & NA \\
\hline $\begin{array}{l}\text { Zafar and Javed/ } \\
\text { ESJ/2013 }\end{array}$ & $\begin{array}{l}-35 \text { for } \mathrm{Mn} \\
\text { premolars }\end{array}$ & In vivo/85 images & 94.6 \\
\hline $\begin{array}{l}\text { Sudhakar et al./ } \\
\text { JCDR/2014[112] }\end{array}$ & $\begin{array}{l}-20 \text { to }-25 \text { for Max } \\
-15 \text { to }-20 \text { for Man }\end{array}$ & In vitro/20 images & 90.7 \\
\hline AKUH 2015 & $\begin{array}{l}-20 \text { to }-30 \text { for } M a x \\
+20 \text { to }+30 \text { for } M n \\
10^{\circ} \text { tilt }\end{array}$ & $\begin{array}{l}\text { In vitro mannequin } \\
\text { head/24 images }\end{array}$ & 82.6 \\
\hline
\end{tabular}

for anterior teeth. The extraoral approach is technique sensitive, and it requires precise angulation and positioning so it should be attempted multiple times ex vivo in order to get knowledge and experience. Furthermore, radiographs obtained from extraoral technique have lower image resolution when compared with a standard intraoral radiograph.

\section{CONCLUSIONS}

It appears that the extraoral radiographic method can be used in root length determination in subjects where intraoral radiography is difficult or not possible. We recommended that more studies should be conducted to formulate standard guidelines for angulation of EOPA and to evaluate its accuracy. Standardization of this technique can produce better image quality and errors like overlapping of structures etc., can be avoided.

\section{Acknowledgment}

We would like to acknowledge Dr. Khabir Ahmed (AKUH), who helped us with the statistics.

\section{Financial support and sponsorship}

Nil.

\section{Conflicts of interest}

There are no conflicts of interest.

\section{REFERENCES}

1. Walton RE. Endodontic radiography. In: Torabinejad M, Walton RE, editors. Endodontics: Principles and Practice. $4^{\text {th }}$ ed. St. Louis: Saunders Elsevier; 2009.

2. Whaites E. Periapical radiography. In: Essentials of Dental Radiography and Radiology. $3^{\text {rd }}$ ed. Edinburgh: Churchill Livingstone; 2002. p. 92.

3. Inoue $\mathrm{N}$, Skinner $\mathrm{DH}$. A simple and accurate way to measuring root canal length. J Endod 1985;11:421-7.

4. Sinai I, Seltzer S, Soltanoff W, Goldenberg A, Bender IB. Biologic aspects of endodontics. II. Periapical tissue reactions to pulp extirpation. Oral Surg Oral Med Oral Pathol 1967;23:664-79.

5. Kim-Park MA, Baughan LW, Hartwell GR. Working length determination in palatal roots of maxillary molars. J Endod 2003;29:58-61.

6. Kumar R, Khambete N, Priya E. Extraoral periapical radiography: An alternative approach to intraoral periapical radiography. Imaging Sci Dent 2011;41:161-5.

7. Newman ME, Friedman S. Extraoral radiographic technique: An alternative approach. J Endod 2003;29:419-21.

8. Chen $\mathrm{CH}$, Lin SH, Chiu HL, Lin YJ, Chen YK, Lin LM. An aiming device for an extraoral radiographic technique. J Endod 2007;33:758-60.

9. Reddy SS, Kaushik A, Reddy S, Agarwa K. Extraoral periapical radiography: A technique unveiled. J Indian Acad Oral Med Radiol 2011;23:S336-9.

10. Zafar MS, Javed E. Extra oral radiography: An alternative to intraoral radiography for endodontic (Root Canal System) length determination. Eur Sci J 2013;9:51-61.

11. Saberi E, Hafezi L, Farhadmolashahi N, Mokhtari M. Modified Newman and Friedman extraoral radiographic technique. Iran Endod J 2012;7:74-8.

12. Sudhakar S, Ramaswamy P, Smitha B, Uday G. Utility of extra-oral 


\section{Nazeer, et al.: Extra oral periapical radiograph}

aiming device in imaging periapical regions of posterior teeth. J Clin Diagn Res 2014;8:51-5.

13. Sharma M, Arora V. Determination of working length of root canal. Med J Armed Forces India 2010;66:231-4.

14. Jarad FD, Albadri S, Gamble C, Burnside G, Fox K, Ashley JR, et al. Working length determination in general dental practice: A randomised controlled trial. Br Dent J 2011;211:595-8.

15. Farida A, Maryam E, Ali M, Ehsan M, Sajad Y, Soraya K. A comparison between conventional and digital radiography in root canal working length determination. Indian J Dent Res 2013;24:229-33.

16. Mohan GM, Anand VS. Accuracy of different methods of working length determination in endodontics. IOSR J Dent Med Sci 2013;12:25-38

17. Jayasinghe RD, Weerakoon BS. Quality of working length radiographs taken and used by dental students during endodontic treatment. Int
J Mod Altern Med Res 2013;1:1-4.

18. Parks ET, Williamson GF. Digital radiography: An overview. J Contemp Dent Pract 2002;3:23-39.

\begin{tabular}{|l|l|}
\hline \multicolumn{2}{|c|}{ Access this article online } \\
\hline Quick Response Code: & \\
\hline
\end{tabular}

